\title{
Sex difference in recombination frequency in Arabidopsis
}

\section{Yu. Vizir and}

\author{
A. B. Korol
}

Institute of Ecological Genetics of Moldavian Academy of Sciences, Kishinev 277018, USSR.

Sex differences for if have been studied in all five chromosomes of the Arabidopsis genome. These differences are strongly segment-specific: in some cases the level of crossing over in male and female meiosis was about the same, though for the majority of segments the $\mathrm{rf}_{\delta}$ is significantly higher than $\mathrm{rf}_{q}$. The data are discussed in the light of the hypothesis about the possible mechanisms of plant sex differences for recombination. The necessity of taking into account the rf sex differences in recombination experiments is called for by the fact that male and female meiocytes can react differentially to the same factor.

\section{INTRODUCTION}

The effect of sex on the crossing over was established as far back as in the early recombination studies. In particular it was revealed that crossing over is blocked in Drosophila males and silkworm females. These results are reflected in the empirical Haldane-Huxley's rule: if crossing over is considerably reduced or completely absent in meiosis of one sex the latter obligatorily is the heterogametic sex. Later the effect of sex on recombination frequency (rf) was detected in many other animals and in every case of all-or-none sex differences in recombination the Haldane-Huxley's rule holds true. But if crossing over occurs with marked frequences both in male and female meiocytes (i.e., sex differences in rf are of a quantitative nature), the meiotic exchange level in the heterogametic sex may be lower or higher relative to the homogametic one and the deviation of the index $u=\mathrm{rf}_{\delta} / \mathrm{rf}_{q}$ from unity is segment specific. Thus, in the mouse genome $u$ was found to be significantly lower than unity in 30 segments, $u>1$ in five and $u<1$ in 19 (Dunn and Bennett, 1967). With the exception of maize this question is poorly investigated in higher plants in spite of its practical and theoretical importance. In this organism $\mathrm{rf}_{\delta} \geqq \mathrm{rf}_{q}$ for the majority of segments though the magnitude of sex difference in $\mathrm{rf}$ may appreciably depend on genotype (for review see Zhuchenko and Korol,
1985). Some data about sex differences in rf have been obtained from primrose, pea, barley, pine, ryegrass, Arabidopsis, tomato on the basis of marker segregation analysis. For other plants, such differences were revealed cytologically.

In this paper new results of a comparison of crossing over in male and female meiosis in all arabidopsis chromosomes are presented.

\section{MATERIALS AND METHODS}

Stocks with marked chromosome 1 (an'alb1"dis1 and ch1'clv1'ap1), 2 (as'hy1'ert, as'cer8'cp2 and py'hy3), 3 (hy2'gl1), 4 (cp3'cer4'fca and ap2'cer2) and 5 (ttg'lu and yi'hy5) were used (for description see Koornneef et al., 1983). Sex difference in $\mathrm{rf}$ was determined on the basis of reciprocal crosses of F1 with multiple-marker tester. Since Arabidopsis is a self-pollinator and providing testcrosses takes more effort than self-pollination, in some

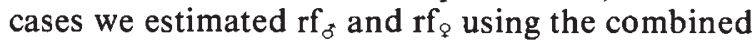
analysis of $\mathrm{F} 2$ and one of the testcrosses, i.e., $\mathrm{F} 1 \times \mathrm{M}$ or $\mathrm{M} \times \mathrm{F} 1$, where $\mathrm{M}$ is the tester. In other words, the second testcross was replaced by the F2. Let us consider, for example, the situation of $\mathrm{M} \times \mathrm{F} 1$ and $\mathrm{F} 2$ combined estimation. Expected frequencies of phenotypes under normal Mendelian segregation of two linked loci $A / a$ and $B / b$ and random syngamy can be represented as 
follows:

$\begin{array}{cllll} & A B & A b & a B & a b \\ \mathrm{~F} 2 & \frac{2+\theta}{4} N 1 & \frac{1-\theta}{4} N 1 & \frac{1-\theta}{4} N 1 & \frac{\theta}{4} N 1 \\ & (n 11) & (n 12) & (n 13) & (n 14) \\ \mathrm{M} \times \mathrm{F} 1 & \frac{1-\mathrm{rf}_{\delta}}{2} N 2 & \frac{\mathrm{rf}_{\delta}}{2} N 2 & \frac{\mathrm{rf}_{\delta}}{2} N 2 & \frac{1-\mathrm{rf}_{\delta}}{2} N 2 \\ & (n 21) & (n 22) & (n 23) & (n 24)\end{array}$

where $\theta=\left(1-\mathrm{rf}_{\delta}\right)\left(1-\mathrm{rf}_{q}\right), \quad N 1$ and N2-the number of plants in F2 and testcross, respectively, $n 1 i$ and $n 2 i$ - the observed frequencies. Using the maximum likelihood method (ML), the estimates of $\mathrm{rf}_{\delta}$ and $\mathrm{rf}_{\varphi}$, as well as sampling variances and covariance can be calculated from the observed segregations by means of Fisher's scoring method (see Bailey, 1961). Then the significance of the difference $\mathrm{rf}_{\delta}-\mathrm{rf}_{q}$ can readily be calculated assuming the asymptotic normality of ML-estimates:

$$
Z=\left(\mathrm{rf}_{\delta}-\mathrm{rf}_{\varphi}\right) /\left[\sigma_{\left(\mathrm{rf}_{\delta}\right)}^{2}+\sigma_{\left(\mathrm{rf}_{\varphi}\right)}^{2}-2 \operatorname{cov}\left(\mathrm{rf}_{\delta}, \mathrm{rf}_{\varphi}\right)\right]^{1 / 2}
$$

\section{RESULTS}

Redei (1969) was the first to point out sex difference in recombination frequency in Arabidopsis. He attributed it to pleiotropic action of the gametophytic mutation Gf located in the chromosome 2. According to Redei, Gf reduces the plant female fertility, causes segregation distortion and sex difference in the crossing over frequency $\left(\mathrm{rf}_{\delta} / \mathrm{rf}_{q}=1.6\right.$ for segment Gf-py). The latter conclusion cannot be considered substantiated because the author established sex difference in rf only in the Gf $\times$ py cross having not compared it with the result obtained on the $\mathrm{Gf}+$ background.

The effect of sex on recombination in Arabidopsis can be indirectly deduced from data of Koornneef et al. (1983). In this paper the direction of test crosses was not indicated, so it is possible to state only the fact of sex differences without their relating to the particular sex. Nevertheless, we calculated from these data the rf values for two sexes and the ratio of the higher value to the lower one. The largest differences were found for the first and fourth chromosomes. The $u$-values for different segments of chromosome 1 were (figures in brackets): an-chl1 (1.43), an-dis1 (2.14), an-dis2 (1.57), chl1-th1 (1.67), dis2-ch1 (1.91); for chromosome 4: hy4-th1 (2.15), hy4-ap2 (1.50), th3-cer2 $(6 \cdot 86)$, th3-ap2 $(2 \cdot 27)$. In contrast, sex differences in $\mathrm{rf}$ are absent in zones chl1-dis1 (chr.1), chl2-er (chr.2), hy4-cer2 and cer2-ap2 (chr.4), ms-ttg (chr.5).

Based on these estimates it is resonable to suppose that the exchange frequencies in male and female meiosis are significantly different in a part of the Arabidopsis genome, although it is unclear where the crossing over rate is higher. The data obtained in our experiments confirm this conclusion and indicate that sex difference in the exchange level is rather the rule than exception for Arabidopsis with recombination occurring much more frequently in male meiosis. In particular, the $\mathrm{rf}_{\delta}$ exceeds the corresponding level of $\mathrm{rf}_{\varphi}$ no less than by a factor of two for the seven out of 13 segments examined, while this excess amounts to 400 per cent and more for four of the segments. The range of $u=\mathrm{rf}_{\delta} / \mathrm{rf}_{q}$ values presented in table 1 accords with the estimates obtained from experimental data of Koornneef et al. (1983). The expediency and even necessity of taking into account the rf sex differences in recombination experiments is called for by the fact that male and female meiocytes can react differentially to the same factor-internal or external. Indeed, let the analysis of crossing over frequency alteration $(\Delta \mathrm{rf})$ be based on estimation of $\mathrm{rf}$ from F2 segregation only. Then, under opposing effects of the factor on $\mathrm{rf}_{q}$ and $\mathrm{rf}_{\delta}$, it is easy to come to the erroneous conclusion that the effect is lacking. But, in view of technical difficulties in performing testcrosses in experiments with self-pollinators the analysis is usually limited to F2. To illustrate the possibility of such a mistake we present some data from a study of relations between transcription and recombination. This problem has been increasingly discussed in the literature in the last decade (Voelkel-Meiman et al., 1987; Thomas and Rothstein, 1989). A more detailed analysis of our data will be given elsewhere.

As a model for analysing this question in Arabidopsis we used the structural gene ch1-2, controlling the nitrate reductase (NR) synthesis-a key enzyme in nitrogen metabolism (OostindierBraaksma et al., 1972). Nitrate ions are known to be specific inductors of nitrate reductase gene transcription, while ammonium ions are repressors of this gene (Acedo, 1978). The changes of the crossing over frequency were analysed in py-hy3 segment surrounding the chl-2 locus (fig. 1).

The buds were treated with equimolar $(0.01 \mathrm{M})$ solutions of tested compound at premeiotic stages. The $\mathrm{KOH}$ treatment was used as an additional control to the $\mathrm{NH}_{4} \mathrm{OH}$ variant. 
Table 1 Sex differences in recombination frequency in Arabidopsis

\begin{tabular}{|c|c|c|c|c|c|c|}
\hline \multirow[b]{2}{*}{ Chr. } & \multirow[b]{2}{*}{ Segment } & \multicolumn{2}{|l|}{ Males } & \multicolumn{2}{|c|}{ Females } & \multirow[b]{2}{*}{$u$} \\
\hline & & $N$ & rf $(\%)$ & $N$ & rf $(\%)$ & \\
\hline \multirow[t]{3}{*}{1} & $\begin{array}{l}\text { ch1-ap1 } \\
\text { ap1-clv1 } \\
\text { ch1-clv1 }\end{array}$ & 435 & $\begin{array}{l}34 \cdot 71 \pm 2 \cdot 28 \\
10 \cdot 57 \pm 1 \cdot 47 \\
39 \cdot 77 \pm 2 \cdot 35\end{array}$ & 422 & $\begin{array}{r}27 \cdot 96 \pm 2 \cdot 28 \\
8 \cdot 53 \pm 1 \cdot 36 \\
35 \cdot 07 \pm 2 \cdot 32\end{array}$ & $\begin{array}{l}1 \cdot 24 * \\
1 \cdot 24 \\
1 \cdot 13\end{array}$ \\
\hline & $\begin{array}{l}\text { an-alb1 } \\
\text { alb1-dis1 } \\
\text { an-dis1 }\end{array}$ & 401 & $\begin{array}{r}17 \cdot 96 \pm 1 \cdot 92 \\
8 \cdot 48 \pm 1 \cdot 39 \\
25 \cdot 44 \pm 2 \cdot 17\end{array}$ & 778 & $\begin{array}{l}4 \cdot 24 \pm 0 \cdot 72 \\
4 \cdot 11 \pm 0 \cdot 71 \\
7 \cdot 84 \pm 0.96\end{array}$ & $\begin{array}{l}4 \cdot 24 * * * \\
2 \cdot 06 * * * \\
3 \cdot 25 * * *\end{array}$ \\
\hline & an-dis 1 & $561^{\#}$ & $20 \cdot 60 \pm 3 \cdot 11$ & 546 & $6.78 \pm 1.07$ & $3 \cdot 04 * * *$ \\
\hline \multirow[t]{2}{*}{2} & as-hyl & $415^{\#}$ & $17 \cdot 73 \pm 3 \cdot 74$ & 85 & $12 \cdot 94 \pm 1 \cdot 50$ & $1 \cdot 37$ \\
\hline & $\begin{array}{l}\text { py-hy3 } \\
\text { as-cer }\end{array}$ & $253^{*}$ & $\begin{array}{l}26 \cdot 67 \pm 3 \cdot 19 \\
24 \cdot 84 \pm 2 \cdot 76\end{array}$ & 401 & $\begin{array}{r}8 \cdot 98 \pm 1 \cdot 12 \\
13 \cdot 37 \pm 1 \cdot 06\end{array}$ & $\begin{array}{l}2 \cdot 97 * * * \\
1 \cdot 86 * * *\end{array}$ \\
\hline 3 & hy2-gl1 & $713^{\#}$ & $40 \cdot 36 \pm 3 \cdot 04$ & 762 & $27 \cdot 82 \pm 1 \cdot 17$ & $1 \cdot 45 * * *$ \\
\hline \multirow[t]{2}{*}{4} & fca-cer 4 & $922^{\#}$ & $47 \cdot 36 \pm 1 \cdot 98$ & 1238 & $11 \cdot 30 \pm 0.68$ & $4 \cdot 19 * * *$ \\
\hline & ap2-cer2 & $1141^{\#}$ & $24 \cdot 48 \pm 1 \cdot 98$ & 361 & $6.09 \pm 0.62$ & $4 \cdot 02 * * *$ \\
\hline \multirow[t]{2}{*}{5} & $\operatorname{ttg}-\mathrm{lu}$ & 918 & $28 \cdot 32 \pm 1 \cdot 05$ & $936^{\#}$ & $5 \cdot 73 \pm 2 \cdot 68$ & $4.94 * * *$ \\
\hline & yi-hy5 & $805^{\#}$ & $50 \cdot 00 \pm 3 \cdot 43$ & 327 & $35 \cdot 47 \pm 1 \cdot 42$ & $1 \cdot 41 * * *$ \\
\hline
\end{tabular}

$*, * *$ and $* * *=P<0.05,0.01$ and 0.001 , respectively; ${ }^{*}=$ the estimation of $\mathrm{rf}$ is based on $\mathrm{F} 2$ and the second testcross; Chr. = chromosome; $N=$ number of plants; $u=\mathrm{rf}_{5} / \mathrm{rf}_{f}$.

Proceeding from the hypothesis of the possible connection between the state of a chromosome region in the germ cell line and the probability of its involvement in the crossing over process (Stern et al., 1975; Zhuchenko and Korol, 1983, 1985), we expect that the nitrate ion treatments will result in changes of recombination between marker loci flanking chl-2. It is this result that has been established in the analysis of treatment consequences based on estimation of $\Delta \mathrm{rf}_{\delta}$ (table 2).

Significant recombinogenic effect of nitrate ions on microsporogenesis can be regarded as evidence (albeit indirect) of connection between chromatin state modulated by transcription induction and crossing over. Application of ammonium

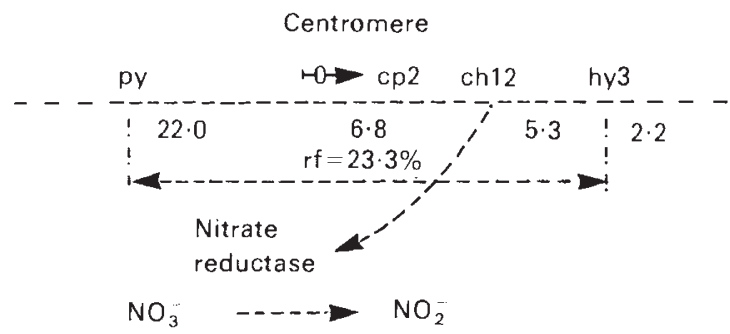

Figure 1 Scheme of the region surrounding the nitrate reductase gene. ions should lead to nonspecific chromatin decompactization (Nokkala et al., 1985) which may promote the exchanges. The opposite direction of changes in megasporogenesis does not contradict this assumption if we take into account two points: (1) the respective stages of megasporogenesis occur later than in microsporogenesis; (2) the ions $\mathrm{NH}_{4}^{+}$and $\mathrm{NO}_{3}^{-}$can be metabolized before the reactive stage sets in with their derivatives (aminoacids) being transcription repressors of the chl-2 gene (Acedo, 1978). The data obtained show that the situations are real when the effect on the crossing over of the factor studied can be detected only by differential analysis of both $\mathrm{rf}_{\delta}$ and $\mathrm{rf}_{q}$ changes.

\section{DISCUSSION}

The obtained data indicate that considerable sex differences in Arabidopsis crossing over frequency are possible. The failure to consider the specificity of $\mathrm{rf}_{\delta}$ and $\mathrm{rf}_{\varphi}$ reactions to internal and external recombinogenic factors is wrought with the risk of a false inference that the effects are small or absent while in reality they are large but $\Delta \mathrm{rf}_{\delta}$ and $\Delta \mathrm{rf}_{q}$ are in opposite directions. The asynchronous proceeding of sensitive to external influence meiotic 
Table 2 Sex differences in recombinogenic action of nitrate reductase gene effectors in the region surrounding this gene

\begin{tabular}{|c|c|c|c|c|c|c|c|}
\hline \multirow[b]{2}{*}{ Treatments } & \multicolumn{3}{|c|}{ Males } & \multicolumn{3}{|c|}{ Females } & \multirow[b]{2}{*}{$u$} \\
\hline & $N$ & $\operatorname{rf}(\%)$ & $\Delta \mathrm{rf}$ & $N$ & rf $(\%)$ & $\Delta \mathrm{rf}$ & \\
\hline Cont. & $133^{\#}$ & $23 \cdot 3 \pm 2 \cdot 3$ & - & $\begin{array}{l}570^{\&} \\
301^{*}\end{array}$ & $\begin{array}{l}16 \cdot 8 \pm 5 \cdot 6 \\
19 \cdot 0 \pm 2 \cdot 6\end{array}$ & - & $\begin{array}{l}1 \cdot 4 \\
1 \cdot 2\end{array}$ \\
\hline $\mathrm{KNO}_{3}$ & $102^{\#}$ & $36 \cdot 3 \pm 2 \cdot 7$ & $+13 \cdot 0 * * *$ & $\begin{array}{l}522^{\&} \\
125^{\#}\end{array}$ & $\begin{array}{r}8 \cdot 2 \pm 7 \cdot 8 \\
12 \cdot 7 \pm 3 \cdot 1\end{array}$ & $\begin{array}{l}-8 \cdot 6 \\
-7 \cdot 3\end{array}$ & $\begin{array}{l}4 \cdot 4 * * \\
2 \cdot 9 * * *\end{array}$ \\
\hline $\mathrm{NH}_{4} \mathrm{OH}$ & $180^{\#}$ & $29 \cdot 4 \pm 1 \cdot 9$ & $+6 \cdot 1 *$ & $\begin{array}{l}945^{8} \\
185^{\#}\end{array}$ & $\begin{array}{l}13 \cdot 7 \pm 5 \cdot 1 \\
10 \cdot 2 \pm 2 \cdot 2\end{array}$ & $\begin{array}{l}-3 \cdot 1 \\
-8 \cdot 8 * *\end{array}$ & $\begin{array}{l}2 \cdot 2 * * \\
2 \cdot 9 * * *\end{array}$ \\
\hline $\mathrm{NH}_{4} \mathrm{NO}_{3}$ & $67^{\#}$ & $31 \cdot 3 \pm 2 \cdot 8$ & $+8 \cdot 0$ & $456^{\#}$ & $9 \cdot 3 \pm 7 \cdot 7$ & $-7 \cdot 5$ & $3 \cdot 4 * *$ \\
\hline $\mathrm{KOH}$ & $113^{\#}$ & $21 \cdot 2 \pm 2 \cdot 8$ & $-2 \cdot 1$ & $321^{\#}$ & $19 \cdot 8 \pm 6 \cdot 9$ & $+2 \cdot 3$ & $1 \cdot 1$ \\
\hline
\end{tabular}

$*$, ** and $* * *=P<0.05,0.01$ and 0.001 , respectively; ${ }^{*}$ and $\#=$ the estimation of $\mathrm{rf}$ is based on $\mathrm{F} 2$ and the second testcross and the testcross, respectively; Cont. $=$ control; $N=$ number of plants; $u=\mathrm{rf}_{\Im} / \mathrm{rf}_{q}$.

stages in micro- and megaspores can be another source of errors. Finally, it must be noted that sex differences of the scale found in Arabidopsis are to be taken into account in genetic mapping. Perhaps, in cases like these it is advisable to calculate both $\mathrm{rf}_{\delta}$ and $\mathrm{rf}_{q}$ along with the average estimate $\left(\mathrm{rf}=1-\sqrt{\left(1-\mathrm{rf}_{\delta}\right)\left(1-\mathrm{rf}_{q}\right)}\right.$ or $\left.\mathrm{rf}=\sqrt{\mathrm{rf}_{\delta} \mathrm{rf}_{q}}\right)$ derived from the F2 analysis (see also Lalouel, 1977; Donis-Keller et al., 1987). When evaluating the meaning of recombination dependence on sex it is necessary to ascertain mechanisms and genetic control of this phenomenon, its role in population adaptation and possible ways of its evolutionary formation. As with previously established cases in other plants (Zhuchenko and Korol, 1985), mechanisms determining the observed differences in Arabidopsis between $\mathrm{rf}_{\delta}$ and $\mathrm{rf}_{q}$ are unknown. Because the results under discussion pertain to situations in which the diversity occurs in different tissues of the same individual or even the same inflorescence (flower), they cannot be attributed to direct influence of genotypic variations.

In principle the observed effect can be due to differential expression in male and female germ cells of genes controlling the crossover frequency and distribution (i.e., changes in the functioning of the "controlling" system conditioned by sex as a state). The other cause is the sex difference in the genomic distribution of segments accessible to action of recombination enzymes (i.e., changes in the "reactive" system). For some species one can suppose this distribution to be dependent on the pattern of heterochromatin distribution provided this effect of heterochromatin on recombination is sex-dependent (Rhoades, 1978). Thus, in the absence of knobs in maize chromosome 3 and 9 the crossing over frequencies in respective segments are the same in the micro- and megasporogenesis, while in their presence the level of $\mathrm{rf}_{\delta}$ is significantly higher than that of $\mathrm{rf}_{\varphi}$. Nevertheless, in our opinion the above hypothesis seems to be rather unreal for the following reasons: the difference between $\mathrm{rf}_{\delta}$ and $\mathrm{rf}_{q}$ in maize is of the same sign as in Arabidopsis, but the latter is characterised by much lower content of highly repeated DNA sequences constituting heterochromatin (Meyerowitz, 1987) and, at the same time, by a much greater level of $\mathrm{rf}_{\delta} / \mathrm{rf}_{q}$.

The other possible mechanism of sex difference connected with differential duration of meiotic prophase was offered by Fogwill (1958) to explain her cytological data on higher chiasma frequency in female meiosis of Fritillaria and Lilium. When applying this hypothesis to Arabidopsis, one can expect male meiosis to be prolonged as compared to the female one.

Finally it is likely that the observed dependence of $\mathrm{rf}$ on sex is due to recombinant selective elimination. For example, the output of recombinants may be lowered when crossover and non-crossover chromatids are orientated nonrandomly relative to the very macrospore of the tetrad which will be converted into the egg cell. This assumption was completely rejected after having being tested experimentally using the el mutation which results in the formation of nonreduced diploid eggs ( Nel, 1975). Another mechanism of selective elimination is the reduction of viability (or competitive ability) of crossover combinations due to break-down of coadapted gene blocks in meiosis of F1 hybrids (Zhuchenko, 1980). This hypothesis cannot either explain our situation with Arabidopsis. Indeed, for 
estimating sex differences in $\mathrm{rf}$ at a set of segments (py-hy3, as-cer8, cer4-fca, hy5-yi) we have used hybrids of crosses between marker stocks derived in the same genetic background (the Landsberg"erecta" race). Therefore, apart from the marker loci, the heterozygosity for adaptively valuable gene complexes was absent and thus there was no possibility for selection against crossover combination with reduced fitness among female gametes. The absence of substantial selection against recombinants in crosses $\mathrm{F} 1(q) \times \mathrm{M}\left(\delta^{*}\right)$ can also be inferred from the fact that a drastic decline of $\mathrm{rf}_{q}$ relative to $\mathrm{rf}_{\delta}$ was observed in spite of a very good conformity of monogenic ratios to the theoretical one and the proximity of reciprocal crossover class numbers.

On the whole, the mechanisms of sex difference in crossing over frequency in hermaphrodite plants remain unknown and it is the goal of future investigations to reveal them. In view of our results, it is worthwhile to use Arabidopsis as a convenient model for such a study.

In conclusion, it must be noted that taking into account the sex differences in crossover exchanges frequency and distribution is of interest not only from a theoretical but also from a practical point of view-as an approach in resolving the problem of enhancing the level and spectrum of genotypic variability in breeding programs (see Zhuchenko and Korol, 1983).

Acknowledgements We wish to thank Dr M. Koornneef for sending a large collection of multimarker lines, which we used in this study. The useful comments of the referee are also acknowledged as well as the help of Mr G. K. Lakhman in preparing the English version of the manuscript.

\section{REFERENCES}

ACEDO, G. H. 1978. An inducible nitrate reductase system in Arabidopsis. Arabid. Inf. Serv. (Frankfurt am Main), 15, 7-9.

BAILEY, N. T. J. 1961. Introduction to the Mathematical Theory of Genetic Linkage. Oxford: Clarendon Press, 298 pp.
DONIS-KEller, H., GREEN, P., HELMS, C., CARTiNhOUR, S., WEIFFENBACH, B., STEPHENS, K., KEITH, T. P., BOWDEN, D. W., SMITH, D. R., LANDER, E. S., BOTSTEIN, D., AKOTS, G., REDIKER, K. S., GRAVIUS, T., BROWN, V. A., RISING, M. B., PARKER, C., POWERS, J. A., WATT, D. E., KAUFFMAN, E. R., BRICKET, A., PHIPPS, P., MULLER-KAHLE, H., FULTON, T. R., NG, S., SCHUMM, J. W., BRAMAN, J. C., KNOWLTON, R. G., BARKER, D. F., CROOKS, S. M., LINCOLN, S. E., DALY, M. J. AND ABRAHAMSON, J. 1987. A genetic linkage map of the human genome. Cell, 51, 319337.

DUNN, L. G. AND BENNETT, D. 1967. Sex differences in recombination of linked genes in animals. Genet. Res., 9, 211-220.

FOGWILL, M. 1958. Differences in crossing-over and chromosome size in the sex cells of Lilium and Fritillaria. Chromosoma, 9, 493-504.

KOORNNEEF, M., VAN EDEN, J., HANHART, C. J., STAM, P., BREAKSMA, F. G. AND FEENSTRA, W. J. 1983. Linkage map of Arabidopsis thaliana. Heredity, 74, 265-272.

LALOUEL, J. M. 1977. Linkage mapping from pair-wise recombination data. Heredity, 38, 61-77.

MEyerowitz, E. M. 1987. Arabidopsis thaliana. A. Rev. Genet., $21,93-111$.

NEL, P. M. 1975. Crossing over and diploid egg formation in the elongate mutant of maize. Genetics, 79, 435-450.

NOKKALA, S. AND NOKKALA, C. 1985. Spiral structures of meiotic chromosomes in plants. Hereditas, 103, 187-194.

OOSTINDIER-BRAAKSMA, F. J. AND FEENSTRA, w. J. 1973. Isolation and characterization of chlorate-resistant mutants of Arabidopsis thaliana. Mut. Res. 19, 175-185.

REDEI, G. P. 1969. A review of genetics and biology of Arabidopsis thaliana (L.) Heynh. Bibl. Genet., 21, 1-151.

RHOADES, M. M. 1978. Genetic Effects of Heterochromatin in Maize. Maize Breeding and Genetics. Wiley, New York, pp. 641-671.

STERN, H., WESTERGAaRD, M. AND WetTSTEIN, D. 1975. Presynaptic events in meiocytes of Lilium longiflorum and their relation to crossing over. Proc. Natl Acad. Sci. USA, 72, 961-965.

THOMAS, B. J. AND ROTHSTEIN, R. 1989. Elevated recombination rates in transcriptionally active DNA. Cell, 56, 619630.

VOELKEL-MEIMAN, K., KEIL, R. L. AND ROEDER, G. S. 1987. Recombination-stimulating sequences in yeast ribosomal DNA correspond to sequences regulating transcription by RNA polymerase I. Cell, 48, 1071-1079.

ZHUCHENKO, A. A. 1980. Ecological Genetics of Cultivated Plants. Shtiintsa Publishers, Kisinev, pp. 1-588.

ZHUCHENKO, A. A. AND KOROL, A. B. 1983. Ecological aspects of the recombination problem. Theor. appl. Genet., 64, 177-185.

ZHUCHENKO, A. A. AND KOROL, A. B. 1985. Recombination in Evolution and Breeding. Nauka, Moscow, pp. 1-400. 